\title{
ГЕЛЬ-ХРОМАТОГРАФИЯ СОЛЮБИЛИЗИРОВАННОГО МУСКАРИНОВОГО РЕЦЕПТОРА
}

\author{
(Представил О. Киррет)
}

Мускариновый рецептор интегрирован в структуре белково-липидных нейрональных мембран и может быть выделен при обработке этих мембран растворами детергентов []. Для количественного определения рецептора используют радиоактивные лиганды, специфически взаимодействующие с этим белком $\left[{ }^{2}\right]$. Если в результате их взаимодействия образуется ковалентный рецептор-лигандный комплекс, то выделение такого меченого белка можно провести в денатурирующих условиях, например раствором Na-додецилсульфата, и анализировать методом полиакриламидгель-электрофореза в присутствии этого же детергента.

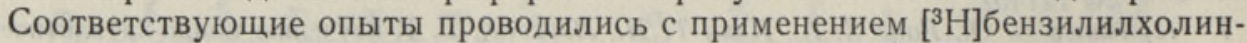
иприта в качестве ковалентной метки рецептора [3]. При этом, например, для меченого этим радиоактивным лигандом полипептидного компонента мускаринового рецептора мозга были получены следующие молекулярные массы, кДа: мозг крысы - $80\left[{ }^{4,5}\right], 83$ [ $\left.^{6}\right]$ и $86\left[{ }^{7-9}\right]$; мозг свиньи $-70\left[{ }^{10}\right] ;$ мозг собаки $-82\left[{ }^{5}\right] ;$ мозг человека $-78\left[{ }^{5}\right]$ и $80\left[^{1{ }^{1}}\right]$; мозг лягушки -80 [ $\left.^{11}\right]$.

Как видно, несмотря на разные источники рецептора, результаты перечисленных работ весьма хорошо совпадают друг с другом.

В то же время значительный интерес представляет изучение молекулярных свойств солюбилизированного нативного рецепторного белка или его обратимого комплекса со специфическими лигандами. В этом случае для характеристики молекулярных свойств рецептора применимы методы седиментационного анализа и гель-хроматографии, не нарушающие связывающих свойств изучаемого комплекса. Кроме того, решающее значение имеет выбор солюбилизирующего агента, так как далеко не все детергенты или их смеси допускают выделение из мембран рецепторного белка, сохраняющего способность специфически взаимодействовать с мускариновыми лигандами [12].

Попытки охарактеризовать молекулярные свойства солюбилизированного мускаринового рецептора или его обратимого комплекса со специфическими лигандами приводили к весьма различным результатам. Так, например, кажущиеся молекулярные массы рецепторной частицы, экстрагированной из мембран мозга крысы 0,8-1,0\%-ным раствором

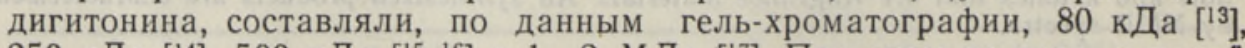
250 кДа [14], 500 кДа $\left[{ }^{15}, 16\right]$ и $1-2$ МДа [ $\left.{ }^{17}\right]$. При этом не ясно, в какой мере такие различия отражают гетерогенность самой изучаемой системы, а в какой мере определяются условиями солюбилизации и проведения анализов или влиянием природы детергента на степень агрегации белков в солюбилизате.

В настоящей работе поставлена цель изучить эти вопросы методом гель-фильтрации в случае рецептор-лигандных комплексов, солюбилизированных дигитонином и Triton X-100. При этом варьировали условия 
солюбилизации и проводили опыты, заменяя детергенты в процессе хроматографического анализа. В качестве радиоактивной метки для идентификации мускаринового рецептора, выделенного из мембран коры больших полушарий мозга крысы, использовали L- $\left[{ }^{3} \mathrm{H}\right]$ хинуклидинилбензилат. Этот лиганд обладает высокой селективностью связывания и отличается малой скоростью диссоциации из комплекса с рецептором $\left[{ }^{13}\right]$, что способствует проведению хроматографических анализов.

\section{Методы исследования}

Методика получения мембранного препарата мускаринового рецептора коры больших полушарий мозга крыс и определения в нем концентрации активных центров по специфическому связыванию L- $\left[{ }^{3} \mathrm{H}\right]-$ хинуклидинилбензилата (38 Қи/ммоль, «Аmersham», Англия) методом фильтрации на стекловолокнистых фильтрах GF/B («Whatman, Англия) описана в $\left[{ }^{18}\right]$. Для солюбилизации рецептора использовали раствор коммерческого препарата дигитонина («Merck», ФРГ, партия 3193823 ), приготовленный по описанной в $\left.{ }^{13}\right]$ методике, или $1 \%$-ный раствор детергента Triton X-100 («Serva», США). Рецептор солюбилизировали в комплексе c L- $\left[{ }^{3} \mathrm{H}\right]$ хинуклидинилбензилатом и определяли его количество методом гель-фильтрации на маленьких колонках Sephadex G-50 $(90 \times 7$ мм $)$, как описано в [ $\left.{ }^{13}\right]$.

Хроматографические анализы солюбилизированного дигитонином рецептора проводили на колонках Sephadex G-200 (тонкий, «Pharmacia», Швеция) и Ultrogel A6 (LKB, Швеция) при $4^{\circ} \mathrm{C}$. Колонки элюировали К-фосфатным буфером с рН 7,40 и ионной силой $0,01,0,05,0,1$ и 0,3. В элюате варьировали концентрацию дигитонина $(0,2,0,06$ и $0,01 \%)$. Солюбилизированный рецептор-лигандный комплекс определяли по связанному с белком радиоактивному лиганду во фракциях, собранных по 1,3 мл. Всего проведено 19 хроматографических анализов. При этом использовали комплект фирмы LKB, Швеция (Uvicord S, насос Microperpex, стандартные колонки $16 \times 850$ мм и коллектор Redi Rac). Скорость элюирования 0,13 мл/мин.

Гель-хроматографию проводили на колонке Ultropack TSK G3000SW $(7,5 \times 300$ мм, LKB, Швеция), пользуясь жидкостным хроматографом высокого давления (ЧССР). Элюировали 0,05 M К-фосфатным буфером c pH 7,40 , содержащим $0,1 \%$ Triton X-100. Скорость элюирования 0,2 мл/мин при давлении 1 МПа.

Колонки калибровали белками из стандартного набора фирмы «Pharmacia» (тироглобулин, ферритин, альдолаза, сывороточный альбумин, яичный альбумин, химотрипсиноген, цитохром). Для калибровки колонок использовали также голубой декстран и ДНФ-аланин.

\section{Результаты и их обсуждение}

Нековалентный комплекс солюбилизированного дигитонином мускаринового рецептора и L-[ $\left.{ }^{3} \mathrm{H}\right]$ хинуклидинилбензилата диссоциируется c временем полупревращения 17,5 ч $\left(25^{\circ} \mathrm{C}\right)$. Такая малая скорость диссоциации комплекса допускает проведение хроматографических анализов при нормальном давлении на колонках Ultrogel A6 и Sephadex G-200. B среде Triton X-100 рецептор-лигандный комплекс менее стабилен, он разлагается с временем полупревращения 2,8 ч $\left(25^{\circ} \mathrm{C}\right)$. Поэтому хроматографические анализы в присутствии этого детергента проводили при высоком давлении на колонке Ultropack TSK G3000SW, время одного опыта не превыщало 0,5 ч. 
Рис. 1. Зависимость константы элюации $K_{a v}$ от логарифма молекулярных масс маркерных глобулярных белков при гель-фильтрацин на колонках Ultropack TSK G3000SW (1), Sephadex G-200 (2), Ultrogel A6 (3) (0,05 M K-фосфатный буфер, pH 7,4). Константа $K_{a v}$ для белка, элюирующегося в объеме $V_{e}$, вычислена по уравнению $K_{a v}=\left(V_{e}-V_{0}\right)$ / $\left(V_{t}-V_{0}\right)$, где $V_{0}-$ свободный объем, $V_{t}-$ полный объем колонки.

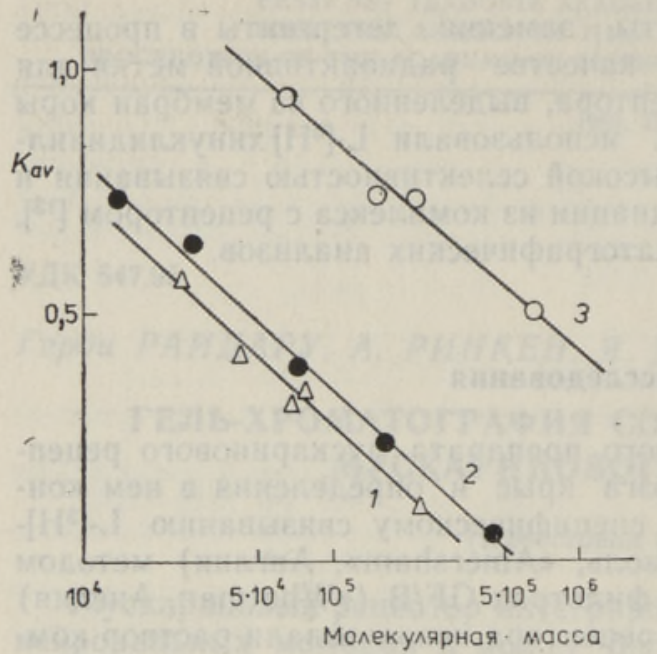

Калибровочные прямые для использованных колонок получали в координатах $K_{a v}$ и логарифм молекулярной массы белка (рис. 1) или радиус частицы по Стоксу [19]. При этом было установлено, что результаты калибровки не меняются при добавлении в используемый для элюирования фосфатный буфер дигитонина до концентрации $0,06 \%$ и Triton X-100 до концентрации $0,1 \%$. Аналогичные результаты известны из $\left[{ }^{20}\right]$. Очевидно, это объясняется гидрофильной природой стандартных белков, которые не взаимодействуют с детергентами. С другой стороны, можно ожидать, что солюбилизированные мембранные белки элюируются вместе с детергентом. Это допускает оценку только қажущейся молекулярной масәы этих частиц или стоксова радиуса комплекса белок-детергент.

На колонках Ultrogel A6 и Sephadex G-200 достигается полное разделение связанного с белком радиоактивного лиганда от избытка свободного лиганда (рис. 2). Так как в присутствии 10 мкM атропинсульфата весь радиоактивный лиганд переходит во фракцию низкомолекулярных веществ, можно заключить, что вместе с белками элюируется и L- $\left[{ }^{3} \mathrm{H}\right]$ хннуклидинилбензилат, специфически связанный с мускариновым рецептором.

Из колонки Ultrogel A6 основная фракция рецептор-лигандного комплекса элюируется в виде пика, характеризуемого константой $K_{a v}=0,65$ (рис. $2, a$ ). По этим данным получим для рецептор-лигандного комплекса радиус по Стоксу $58 \AA$ и кажущуюся молекулярную массу 350 кДа. Так как Ultrogel A6 эффективно разделяет биополимеры с молекулярной массой до 1000 кДа, можно думать, что в дигитониновом солюбилизате мускаринового рецептора нет рецепторных частиц с молекулярной массой больше, чем в основной фракции (350 кДа).

Более детальный анализ состава солюбилизата в области меньших молекулярных масс проводили на колонке Sephadex G-200. В этом случае основная фракция элюируется непосредственно за пиком маркера свободного объема колонки и характеризуется константой $K_{a v}=0,09$ (рис. 2,6$)$. Этот результат также соответствует кажущейся молекулярной массе 350 кДа и совпадает с данными, полученными на колонке Ultrogel A6. Других пиков, разделяющихся от основного, связанного с белком радиоактивного лиганда, на колонке Sephadex G-200 обнаружить не удалось.

Таким образом, солюбилизированный дигитонином мускариновый рецептор элюируется из колонки с 0,06\%-ным раствором этого детергента в виде симметричного пика, что свидетельствует о гомогенной природе рецепторного препарата в солюбилизате. Варьирование ионной силы буферного раствора от 0,01 до 0,3 практически не влияло на 
результаты хроматографического анализа. Кроме того, было установлено, что элюирование колонок буферными растворами, содержащими 0,01 или $0,2 \%$ дигитонина, также не привело к изменению наблюдаемой величины рецепторных частиц. Следовательно, смешанные мицеллы, содержащие рецепторный белок и детергент, можно считать уравнове-
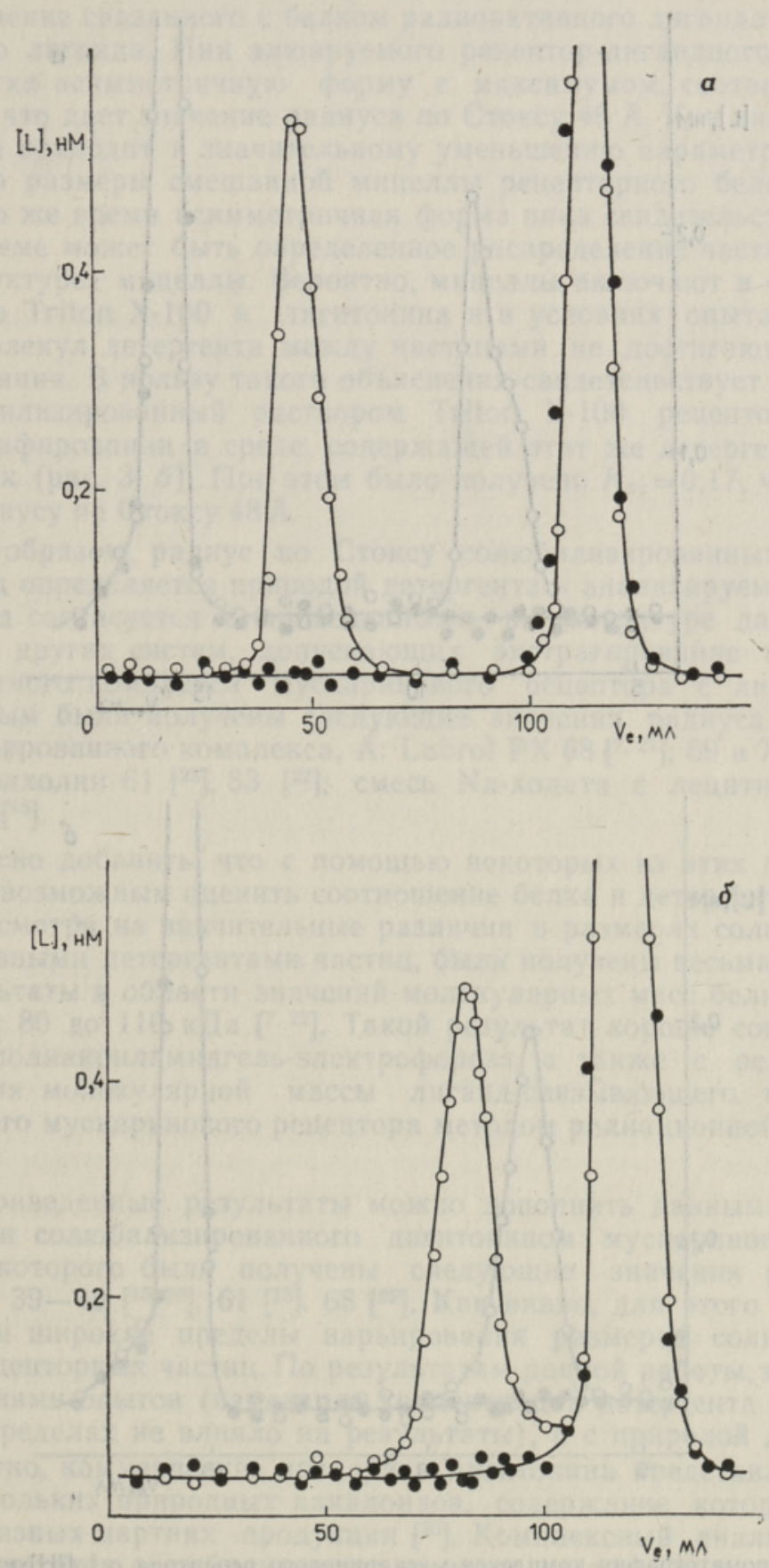

Рис. 2. Гель-хроматография солюбилизированного дигитонином комплекса мускаринового рецептора с L-[3ㄱ]хинуклидинилбензилатом (O) на колонках Ultrogel A6 (a) и Sepha$\operatorname{dex}$ G-200 (б) (0,05 M K-фосфатный буфер, $\mathrm{pH} 7,4,0,06 \%$ дигитонина). Неспецифическое связывание лиганда (-) определено в присутствии 10 мкM атропинсульфата. 
шенными системами, степень диспергирования которых не меняется при варьировании в вышеуказанных пределах как ионной силы буфера, так и концентрации детергента.

В то же время природа детергента значительно влияет на опреде-
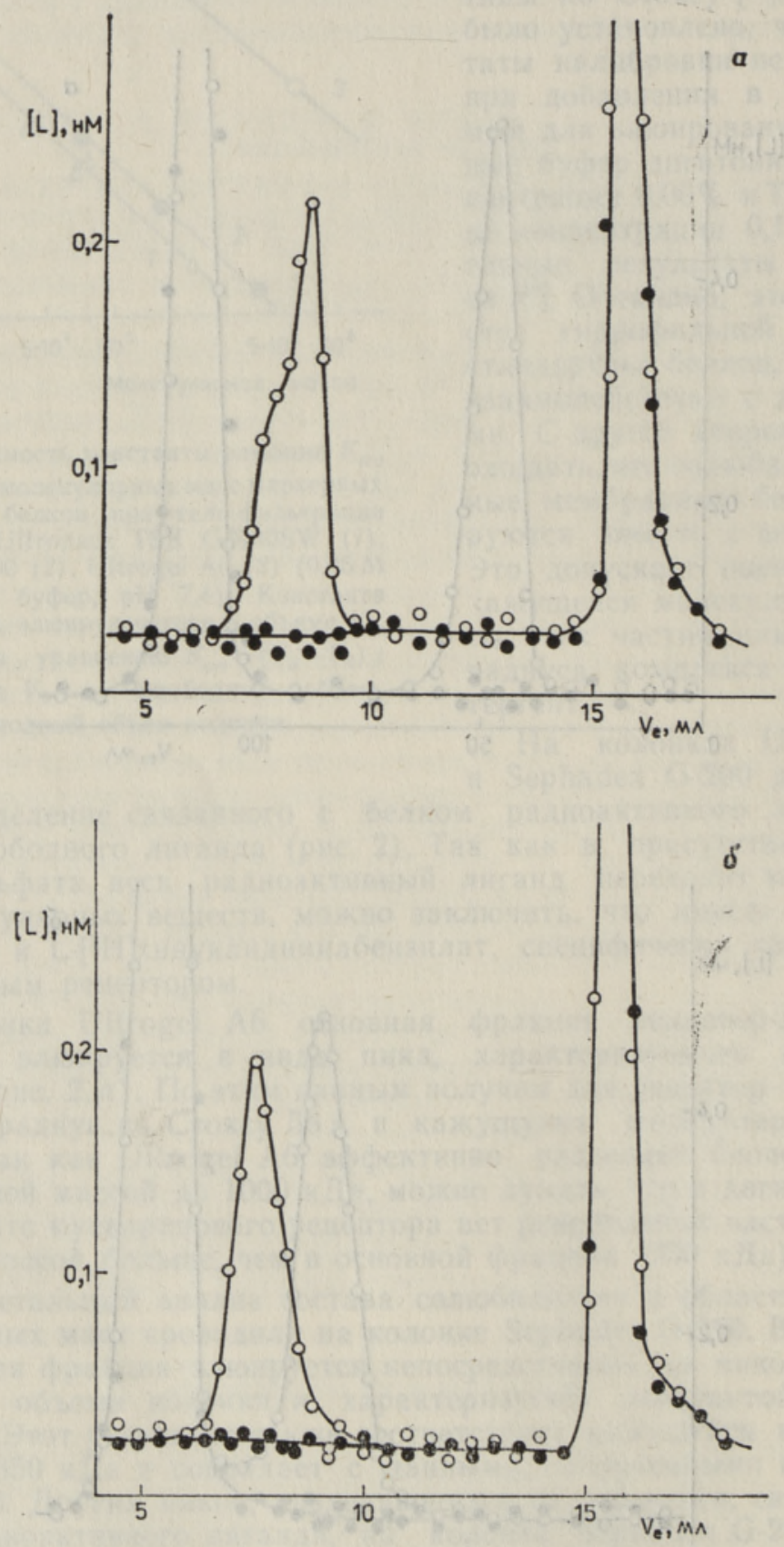

Pис. 3. Гель-хроматография комплекса мускаринового рецептора c L-[ $\left.{ }^{3} \mathrm{H}\right]$ хинуклидинилбензилатом (О) методом высокоэффективной жидкостной хроматографии на колонке Ultropack TSK G3000SW (0,05 M K-фосфатный буфер, pH 7,4, 0,1\% Triton X-100). Peцептор-лигандный комплекс солюбилизирован растворами 0,3\%-ного дигитонина (а) или $1 \%$-ноro Triton X-100 (б). Элюация неспецифически связанного лиганда (O) опре. делена в присутствии 10 мкM атропинсульфата. 
ляемые гель-хроматографией параметры солюбилизированных рецепторных частиц. Это видно по результатам, полученным на колонке Ultropack TSK G3000SW в режиме замены детергента (рис. 3,a). В этих опытах использовали солюбилизированный дигитонином рецептор, который наносили на колонку и хроматографировали в среде $0,1 \%$-ного раствора Triton X-100. В таких условиях также достигается эффективное разделение связанного с белком радиоактивного лиганда от избытка свободного лиганда. Пик элюируемого рецептор-лигандного комплекса имеет слегка асимметричную форму с максимумом, соответствующим $K_{a v}=0,22$, что дает значение радиуса по Стоксу $46 \AA$. Как видно, замена детергента приводит к значительному уменьшению параметра, характеризующего размеры смешанной мицеллы рецепторного белка и детергента. В то же время асимметричная форма пика свидетельствует о том, что в системе может быть определенное распределение частиц по величине (структуре) мицеллы. Вероятно, мицеллы включают в себя разное количество Triton X-100 и дигитонина и в условиях опыта процессы обмена молекул детергента между частицами не достигают равновесного состояния. В пользу такого объяснения свидетельствует и тот факт, что солюбилизированный раствором Triton X-100 рецептор дает при хроматографировании в среде, содержащей этот же детергент, симметричный пик (рис. 3, б). При этом было получено $K_{a v}=0,17$, что соответствует радиусу по Стоксу $48 \AA$.

Таким образом, радиус по Стоксу солюбилизированных рецепторных частиц определяется природой детергента в анализируемой системе. Этот вывод согласуется с приведенными в литературе данными для некоторых других систем, допускающих экстрагирование из мембран нековалентного комплекса мускаринового рецептора с лигандом. По этим данным были получены следующие значения радиуса по Стоксу солюбилизированного комплекса, А̊: Lubrol PX $68\left[\left[^{7,21}\right] ; 69\right.$ и $71\left[^{[2]}\right]$; лизофосфатидилхолин $61\left[{ }^{23}\right], 83$ [22]; смесь Na-холата с лецитином $67\left[{ }^{24}\right]$; CHAPS $86\left[{ }^{15}\right]$.

Интересно добавить, что с помощью некоторых из этих детергентов оказалось возможным оценить соотношение белка и детергента в мицеллах [7]. Несмотря на значительные различия в размерах солюбилизированных разными детергентами частиц, были получены весьма совпадающие результаты в области значений молекулярных масс белкового компонента от 80 до $110 \mathrm{kДа} \mathrm{[7,} \mathrm{22].} \mathrm{Такой} \mathrm{результат} \mathrm{хорошо} \mathrm{согласуется} \mathrm{с}$ данными полиакриламидгель-электрофореза, а также с результатами определения молекулярной массы лиганд-связывающего компонента мембранного мускаринового рецептора методом радиационной инактивации.

Вышеприведенные результаты можно дополнить данными гель-хроматографии солюбилизированного дигитонином мускаринового рецептора, для которого были получены следующие значения радиуса по Стоксу, $\AA$ : $39-40\left[{ }^{13,20}\right], 61\left[{ }^{15}\right], 68\left[{ }^{22}\right]$. Как видно, для этого детергента характерны широкие пределы варьирования размеров солюбилизированных рецепторных частиц. По результатам данной работы, это связано не с условиями опытов (изменение концентрации детергента в довольно широких пределах не влияло на результаты), а с природой детергента. Как известно, коммерческие препараты дигитонина представляют собой смеси нескольких природных алкалоидов, содержание которых варьируется в разных партиях продукции $\left[{ }^{25}\right]$. Комплексный анализ зависимости результатов солюбилизации рецептора от состава дигитонина до сих пор не проведен, отчего нельзя определить, какие компоненты коммерческого препарата отвечают за эффективность солюбилизации нативного рецептора. Можно лишь высказать предположение, что изменение величины мицелл солюбилизированного рецептора связано с раз- 
ным составом детергента. Наши предварительные данные подтверждают такой вывод. Экспериментальная проверка этого предположения требует проведения систематического анализа препаратов детергента, используемых для солюбилизации рецептора, и сопоставления полученных данных с результатами анализа солюбилизата.

\section{Л ИТЕРАТУРА}

1. Sokolovsky, M. Muscarinic receptors in the central nervous system. - Int. Rev. Neurobiol., 1984, 25, 139-183.

2. Yamamura, H. I., Snyder, S. H. Muscarinic cholinergic binding in rat brain. Proc. Nat. Acad. Sci. USA, 1974, 71, 1725-1729.

3. Birdsall, N. J. M., Burgen, A. S. V., Hulme, E. C. A study of the muscarinic receptor by gel electrophoresis. - Brit. J. Pharm., 1979, 66, 337-342.

4. Venter, J. C., Fraser, C. M. The structure of adrenergic, dopaminergic and muscarinic receptors. - Periodium Biologorum, 1983, 85, Suppl. 2, 67-74.

5. Venter, J. C. Muscarinic cholinergic receptor structure. Receptor size, membrane orientation and absence of major phylogenetic structural diversity. - J. Biol. Chem., 1983, 258, N 8, 4842-4848.

6. Birdsall, N. J. M., Burgen, A. S. V., Hulme, E. C. Multiple classes of muscarinic receptor binding sites in the brain. - In: Receptors. Proc. 7th Int. Congr. Pharmacol., Paris, 1978. Oxford et al., 1979, 73-80.

7. Haga, T. Molecular size of muscarinic acetylcholine receptors of rat brain. - FEBS Lett., $1980,113, \mathrm{~N} 1,68-72$.

8. Amitai, G., Avissar, S., Balderman, D., Sokolovsky, M. Affinity labeling of muscarinic receptors in rat cerebral cortex with a photolabile antagonist. - Proc. Nat. Acad. Sci. USA, 1982, 79, N 2, 243-247.

9. Avissar, S., Amitai, G., Sokolovsky, M. Oligomeric structure of muscarinic receptors is shown by photoaffinity labeling: Subunit assembly may explain high- and low-affinity agonist states. - Proc. Nat. Acad. Sci. USA, 1983, 80, N 1, 156159.

10. Haga, K., Haga, T., Ichiyama, A., Katada, T., Kurose, H., Ui, M. Functional reconstitution of purified muscarinic receptors and inhibitory guanine nucleotide regulatory protein. - Nature, 1985, 316, N 6030, 731-733.

11. Venter, J. C., Eddy, B., Hall, L. M., Fraser, C. M. Monoclonal antibodies detect the conservation of muscarinic cholinergic receptor structure from Drosophila to human brain and detect possible structural homology with $\alpha_{1}$-adrenergic receptor. - Proc. Nat. Acad. Sci. USA, 1984, 81, 272-276.

12. Ринкен А. А., Лангел Ю. Л., Ярв Я. Л. Солюбилизация некоторыми детергентами мускаринового холинорецептора и его комплекса с хинуклидинилбензилатом. Биохимия, 1987,52 , № $2,303-310$.

13. Ринкен А. А., Лангел Ю. Л., Ярв Я. Л. Солюбилизация дигитонином мускаринового холинорецептора и его комплекса с хинуклидинилбензилатом. - Бнол. мембраны, 1984, 1, № 4, 341-348.

14. Berrie, C. P., Birdsall, N. J. M., Hulme, E. C., Keen, M., Stockton, J. M. Solubilization and characterization of high and low affinity pirenzepine binding sites from rat cerebral cortex. - Brit. J. Pharm., 1985, 85, N 3, 697-703.

15. Baron, B., Gavish, M., Sokolovsky, M. Heterogeneity of solubilized muscarinic cholinergic receptors: binding and hydrodynamic properties. - Arch. Biochem. Biophys., 1985, 240, N 1, 281-296.

16. Luthin, G. R., Wolfe, B. B. Characterization of $\left[{ }^{3} \mathrm{H}\right]$ pirenzepine binding to muscarinic cholinergic receptors solubilized from rat brain. - J. Pharmacol. Exp. Ther., $1985,234, \mathrm{~N} 1,37-44$.

17. Gorissen, H., Aerts, G., Ilien, B., Laduron, P. Solubilization of muscarinic acetylcholine receptors from mammalian brain: an analytical approach. - Anal. Biochem., 1981, 111, N 1, 33-41.

18. Лангел Ю. Л., Ринкен А. А., Тяхепылд Л. Я., Ярв Я. Л. Кинетика инактиващни мускаринового холинорецептора. - Нейрохимня, 1982, 1, № 4, 343-351.

19. Детерман $\Gamma$. Гель-хроматография. М., 1970, 158-166.

20. Manalan, A. S., Werth, D. K., Jones, L. R., Watanabe, A. M. Enrichment: Solubilization and partial characterization of digitonin-solubilized muscarinic receptors derived from canine ventricular myocardium. - Circulat. Res., 1983, 52, N 6, $664-676$.

21. Haga, T. Characterization of muscarinic acetylcholine receptors solubilized by L- $\alpha$ lysophosphatidylcholine and Lubrol PX. - In: Pharmacology and Biochemica! Aspects of Neurotransmitter Receptors. New York, 1983, 43-58, 
22. Berrie, C. P., Birdsall, N. J. M., Haga, K., Haga, T., Hulme, E. C. Hydrodynamic properties of muscarinic acetylcholine receptors solubilized from rat forebrain. Brit. J. Pharm., 1984, 82, 839-851.

23. Nukina, I. Characteristics of muscarinic acetylcholine receptors in rat brain. Acta Med. Okayama, 1983, 37, N 3, 179-191.

24. Hulme, E. C., Berrie, C. P., Haga, T., Birdsall, N. J. M., Burgen, A. S. V., Stockton, J. Solubilization and molecular characterization of muscarinic acetylcholine receptors. - J. Receptor Res., 1983, 3, N 1-2, 301-311.

25. Repke, H., Matthies, H. Preparative separation of digitonin and gitonin, and characterization of its detergent properties. - Pharmazie, 1980, 35, N 4, 233234.

Тартуский государственный университет
Поступила в редакцию

9/VII 1987

\section{Gerda RAIDARU, A. RINKEN, J. JARV}

\section{SOLUBILISEERITUD MUSKARIINSE RETSEPTORI GEELKROMATOGRAAFIA}

Artiklis on käsitletud solubiliseeritud muskariinse retseptori geelkromatograafiat kolonnidega Sephadex G-200 ning Ultrogel A6, aga ka kõrgsurve vedelikukromatograafiat kolonniga Ultropack TSK G3000SW. On leitud, et digitoniini lahuses elueerub retseptor sümmeetrilise piigina, andes Stokesi raadiuseks $58 \AA$. Elueerides puhvriga, milles on Triton X-100, saadi mitsell, mis sisaldas muskariinset retseptorit, Stokesi raadiuseks $46 \AA$. On järeldatud, et mitselli suurus, milles solubiliseerub roti aju muskariinne retseptor, sõltub otseselt kasutatud detergendist. Samas on näidatud, et detergendi kontsentratsiooni ja lahuse ioonse jõu varieerimine ei mõjuta vaadeldava mitselli suurust.

\section{Gerda RAIDARU, A. RINKEN, J. JARV}

\section{GEL-CHROMATOGRAPHY OF SOLUBILIZED MUSCARINIC RECEPTOR}

Muscarinic receptor of rat cerebral cortex and its complex with L-[3H]quinuclidinyl benzilate was solubilized in $\mathrm{K}$-phosphate buffers $(0.05 \mathrm{M}, \mathrm{pH} 7.40)$, containing digitonine or Triton X-100.

The molecular properties of the solubilized receptor were studied by making use of gel-chromatography on Sephadex G-200 and Ultrogel A6 columns as well as on Ultropack TSK G3000SW HPLC column. It has been found that in digitonine solution the receptor is eluated in a symmetrical pike corresponding to the Stokes radius of the particles $58 \mathrm{~A}$. In the buffer which contains Triton X-100, the receptor particles were characterized by the Stokes radius of $46 \AA$. It was concluded that the apparent diameter of micelle which involves the receptor protein is determined by the nature of the detergent used in the medium. The different composition of the preparations of the natural detergent digitonine seems to be the reason why the micelles of solubilized receptor molecules have various sizes reported by different authors. On the other hand, the results obtained show that the detergent concentration as well as the ionic composition of the buffer play no essential role in determining the size of solubilized receptor particles. 